\title{
Tuberculosis Incidence and Mortality Rates Among People Living with HIV Receiving Antiretroviral Therapy at the Buea Regional Hospital: A Seven Year Retrospective Study
}

\author{
Henry Dilonga Meriki ${ }^{1,2,3}$, Kah Emmanuel Nji ${ }^{2,3, *}$, Kukwah Anthony Tufon ${ }^{1,2}$, Yaoh Adolf Tah ${ }^{3}$, \\ Pascal Nji Atanga ${ }^{5}$, Anna Longdoh Njunda ${ }^{4}$, Irene Ane Anyangwe ${ }^{1}$ \\ ${ }^{1}$ Department of Microbiology and Parasitology, University of Buea, Buea, Cameroon \\ ${ }^{2}$ TB Diagnostic Unit, Regional Hospital Buea, Buea, Cameroon \\ ${ }^{3}$ Department of Public Health and Hygiene, University of Buea, Buea, Cameroon \\ ${ }^{4}$ Department of Medical Microbiology and Parasitology, University of Buea, Buea, Cameroon \\ ${ }^{5}$ Cameroon Baptist Convention Health Service, Mutengene, Cameroon
}

\section{Email address:}

merilonga@yahoo.com (H. D. Meriki), kahemmanuel@ymail.com (K. E. Nji), drkapt@yahoo.com (K. A. Tufon), yataldof85@yahoo.ca (Y.A. Tah), njiatanga@yahoo.com (P. N. Atanga), moc.oohay@adnujn_nna (A. L. Njunda), ireneanyangwe@yahoo.com (I. A. Anyangwe)

${ }^{*}$ Corresponding author

\section{To cite this article:}

Henry Dilonga Meriki, Kah Emmanuel Nji, Kukwah Anthony Tufon, Yaoh Adolf Tah, Pascal Nji Atanga, Anna Longdoh Njunda, Irene Ane Anyangwe. Tuberculosis Incidence and Mortality Rates Among People Living with HIV Receiving Antiretroviral Therapy at the Buea Regional Hospital: A Seven Year Retrospective Study. International Journal of HIV/AIDS Prevention, Education and Behavioural Science. Vol. 5, No. 2, 2019, pp. 82-90. doi: 10.11648/j.ijhpebs.20190502.11

Received: May 20, 2019; Accepted: June 25, 2019; Published: July 31, 2019

\begin{abstract}
Introduction: The use of antiretroviral therapy (ART) has dramatically decreased HIV-associated morbidity and mortality in high-and low-income countries with a corresponding reduction in tuberculosis (TB) incidence. Nevertheless, the risk of TB remains substantially higher in people living with HIV (PLHIV) compared to non-HIV infected individuals. In Cameroon, free ART was introduced in 2007 and our understanding of the possible role of ART in reducing HIV-associated TB remains limited. We assessed TB incidence, mortality and risk factors for TB and mortality among PLHIV treated at Buea Regional Hospital between 2008 and 2014. Materials and Methods: In a retrospective study we reviewed the records of 1,477 HIV patients on ART. The data was entered and analysed using SPSS version 21. Bivariate and Multivariate logistic regression analysis were used to determine the risk factors associated with TB and mortality occurrences at 5\% significance level. Results: Of the 1477 patients' records that was reviewed, females $(70.7 \%)$ constituted a greater proportion. Majority of the participants (60.5\%) were between the ages $21-40$ years (mean: $37.5 \pm 11.5$. SD). A total of 209 patients developed TB giving an overall TB incidence density rate $4.25 / 100 \mathrm{PYR}(95 \% \mathrm{CI}$ : 2.47-6.46). There was an increasing trend in the incidence of TB over the years from 1.69 (95\% CI: $0.72-1.98)$ in 2008 to 19.63 (95\% CI: 7.36-21.20) in 2014. The overall mortality rate was $12.4 \%(183 / 1477)$ of which $38.8 \%(71 / 183)$ of them were on TB treatment or previously treated for TB. In a multivariate analysis, low CD4 cells level at ART initiation (AOR: 1.3, 95\% CI: 1.11-.2.10), WHO HIV clinical stage 3 and 4 (AOR: 1.52, 95\% CI: 1.01-2.22) were significantly associated with increase odds of TB occurrence. Conclusion: Even in the era of HAART, TB still remains a significant cause of mortality among PLHIV and therefore efforts should be scaled-up for early diagnosis and prompt treatment of TB.
\end{abstract}

Keywords: Antiretroviral Therapy, Incidence, Mortality, Tuberculosis, PLHIV

\section{Introduction}

HIV and Tuberculosis (TB) are so closely connected that their relationship is often described as a co-epidemic. In the last 15 years the number of new TB cases has more than doubled in countries where the number of HIV infections are also high. [1, 2, 3] In 2014, among the 1.5 
million people who died of TB, 1.1 million were HIVPositive and 0.4 million were HIV-negative cases. [2] Infection with HIV is an established risk factor for acquiring and developing tuberculosis, and the recent increase in the worldwide prevalence of HIV infection has contributed to the rising global incidence of TB with synergistic interaction between HIV and Mycobacterium tuberculosis, each fuelling the other. $[4,5]$ Therefore, the HIV/AIDS pandemic is responsible for the resurgence of TB worldwide, resulting in increased morbidity and mortality. [6, 7] Even in antiretroviral (ART) treated patients, TB is the most common presenting illness. [8, 9] HIV infected patients on HAART have a tuberculosis incidence rate of 5.4 cases/100 person-years, approximately 10-15 times higher than tuberculosis incidence rates in HIV-negative patients in the same community. [10] Of the estimated 36.7 million HIV positive TB patients globally in $201780 \%$ of these patients live in sub-Saharan Africa. [11] At least one third of the 36.7. million PLHIV worldwide are infected with tuberculosis resulting in an estimated 8 million new cases of TB and nearly 2 million deaths each year. [12] In subSaharan Africa, the rates of HIV/TB co-infection exceed 1000 per 100,000 populations. [13] However, as HIV expands in other parts of the world, such as in South-east Asia, the interaction between these two pathogens will continue to expand and compound the health issues related to both infections. Contact with infectious person, lack of knowledge on how to prevent tuberculosis, environmental factors like poor ventilation, overcrowding or living under promiscuous conditions, gender, and previous history of tuberculosis, smoking, low CD4 cells are among the risk factors associated with the occurrence of tuberculosis in HIV/AIDS patients on Antiretroviral therapy. [14]

Cameroon is among the sub-Saharan African countries most severely affected by TB and HIV/AIDS epidemic. The national HIV/AIDS prevalence rate among adults was estimated to be $4.3 \%$ for the year 2011. [15] In May 2007, the Ministry of Public Health as part of national strategy to combat HIV/AIDS declared antiretroviral drugs free to all eligible HIV infected patients with the objective to reduce morbidity and mortality among HIV infected persons. This has dramatically decreased HIV-associated morbidity and mortality with an expected corresponding reduction in TB incidence. Nevertheless, the risk of TB remains substantially higher in people leaving with HIV/AIDS (PLHIV) compared to non-HIV infected individuals. [10] TB and HIV/AIDS programmes were integrated to establish and strengthen the mechanisms for service delivery in order to reduce the burden of TB in PLHIV with ART as an important component. [16] Data is needed to understand the role of ART in TB control especially in PLHIV. Unfortunately, there has been little assessment of the mortality and TB incidence rate in many HIV treatment centres, which prompted this survey at the Buea HIV/AIDS/TB treatment centre between 2008 and 2014.

\section{Nmaterials and Methods}

\subsection{Study Design}

This was a retrospective cohort study design where medical records of HIV/AIDS patients who started treatment as from the $1^{\text {st }}$ of January 2008 to $31^{\text {st }}$ of December 2014 were reviewed, socio-demographic information as well as clinical and laboratory information were obtained from the records.

\subsection{Study Area and Setting}

The study was conducted in the HIV treatment unit of the Buea Regional Hospital. The center was created in 2005, its currently one of the HIV management units of the south west region with about 2005 patients currently in care. It is also a referral hospital as it hosts a TB diagnostic and treatment centre.

\subsection{Study Population and Outcome Definitions}

All medical records of patients registered and treated at the centre from $1^{\text {st }}$ January 2008 to $31^{\text {st }}$ December 2014 were reviewed. Incidence cases of TB were considered 3 months after HIV diagnosis so as to avoid prevalent cases. Hence our primary outcome was incidence of TB. An incident TB case was defined as any client who developed signs and symptoms of TB and was diagnosed TB positive after initiating ART treatment for at least three months Death cases were only those who started treatment between 2008 and 2014 and died within these years. The death causes were deaths due to all causes not limited to TB.

\subsection{Study Procedure}

\subsubsection{Data Collection and Analysis}

Data was extracted from patients' medical records by a trained assistant research officer. The data collected included: - Socio-demographic (Gender, occupation, age, marital status, year of commencement of treatment); clinical (TB status, CD4 count level) and behavioural (alcohol and smoking history). The data were checked for completeness, cleaned and entered into excel spread sheet and analyzed using SPSS version 21.

Descriptive statistics were used to determine the frequencies and percentage of gender, age, occupation, educational level, and marital status. Differences in proportion and incidence were compared using the chi-square test. TB disease incidence density in this HIV-cohort was calculated as the number of new TB-episodes per 100 person-years (PYR) of follow-up. Univariate and multivariate logistic regression analyses were used to determine the risk factors associated with TB infection. Socio-demographic and clinical variables that had a $p$-value of $\leq 0.2$ in the bivariate analysis were included in the multivariate model to control for confounders. All analyses were done at $95 \%$ confidence interval and $p$-value $<0.05$ was considered statistically significant. 


\subsubsection{Ethical and Administrative Consideration}

Ethical clearance was provided by the Institutional Review Board of Buea University and administration approval to access the facility and use the records was provided by the Regional Delegate of Public Health and the director of the hospital.

\section{Results}

\subsection{Socio-demographic Characteristics of Study Participants}

A total of 1558 patients were registered at the centre between 2008 and 2014. Of these, 1477 patients' medical records met the inclusion criteria and were reviewed (Figure 1).

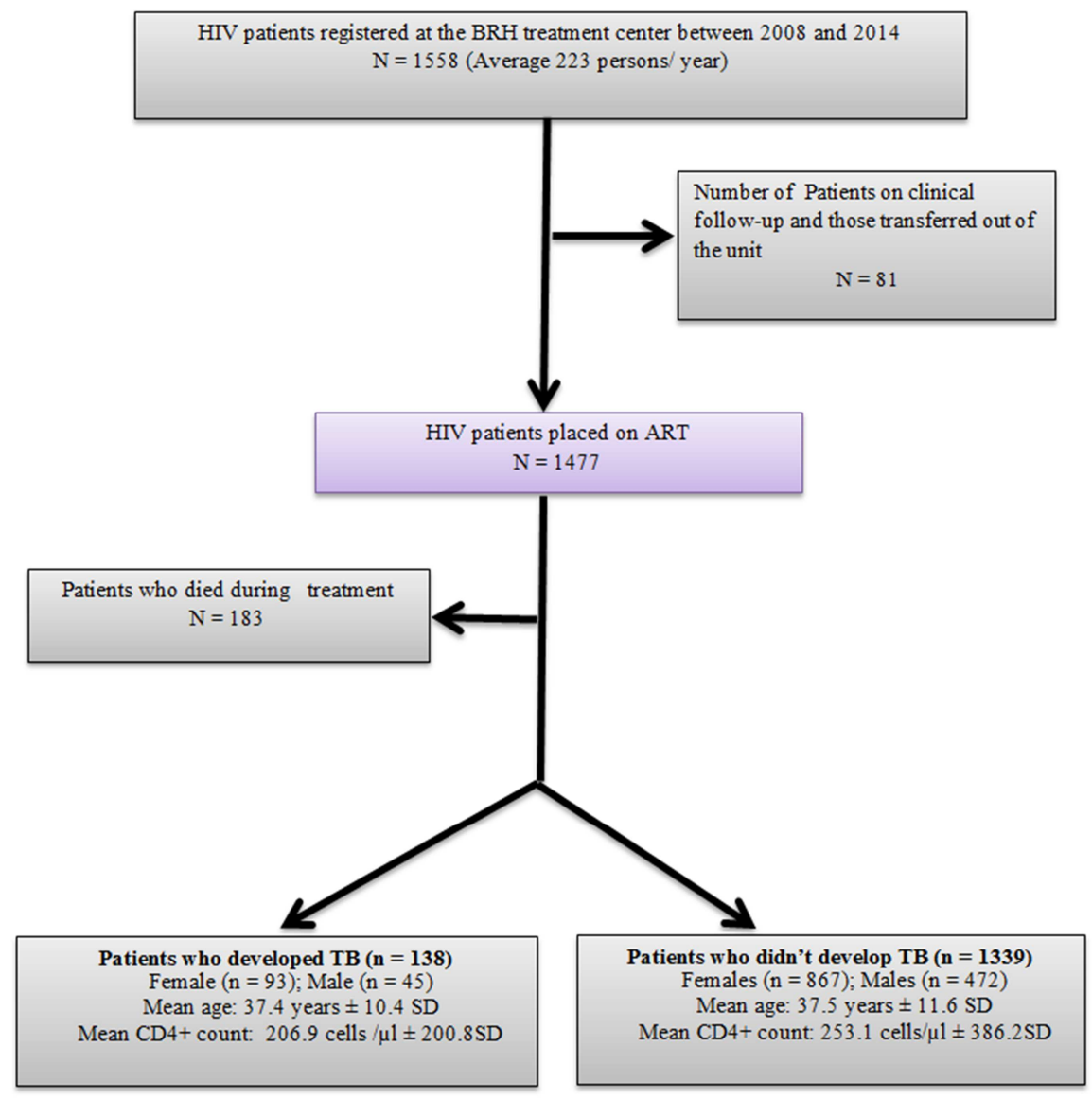

Figure 1. Patient enrolment flow chart.

Of the 1477 patient enrolled, females constituted a greater proportion $(70.7 \%)$ of the study population. Majority $(60.5 \%)$ of them were aged between 21- 40 years with a mean age of 37.5. Six hundred and twenty participants $(41.9 \%)$ were businessmen and women, those who were farmers made up $25.5 \%$ of the study population. A few (6.8\%) were housewives and those who had no jobs. Students made up the minority $(6.7 \%)$ of the study population. A vast majority of the participants (95.9\%) were self-declared Christians. Muslims participants made up just $1.8 \%$ of the study population meanwhile those belonging to other religion were thirty-four $(2.3 \%)$. More than half $(66.9 \%)$ of the participants were single/divorce, and those that were married made up $33.9 \%$ of the study participants. A majority $(42.7 \%)$ had attended primary school meanwhile $36(2.4 \%)$ had not attended primary school at all. Just $9.3 \%$ of the participants had been to the university (Table 1).
Table 1. Sociodemographic characteristics of participants.

\begin{tabular}{llll}
\hline Variables & Categories & Frequency & Percentage \\
\hline \multirow{4}{*}{ Age (years) } & $0-20$ & 67 & 4.5 \\
& $21-40$ & 894 & 60.5 \\
& $41-60$ & 473 & 32.0 \\
Gender & $60+$ & 43 & 2.9 \\
Marital & Males & 433 & 29.3 \\
status & Females & 1044 & 70.7 \\
& Married/cohabiting & 489 & 33.9 \\
Educational & Single/divorce/separated & 988 & 66.9 \\
level & No school & 36 & 2.4 \\
& Primary & 631 & 42.7 \\
& Secondary & 672 & 45.5 \\
Religion & Tertiary & 138 & 9.3 \\
& Christians & 1417 & 95.9 \\
& Muslims & 26 & 1.8 \\
& Others & 34 & 2.3 \\
& Farmers & 377 & 25.5 \\
& Employed & 265 & 17.9 \\
Occupation & No job/housewives & 101 & 6.8 \\
& Business & 620 & 41.9 \\
& Student/Pupils & 114 & 7.7 \\
\hline \multirow{5}{*}{ (a) } & &
\end{tabular}




\subsection{Tuberculosis Incidence Density Rate Stratified by Baseline Socio-demographic and Clinical Characteristics}

A total of 1477 HIV patients were studied with a total duration of follow-up of 5051 person years. Of this 1477 patients, 209 (14.2\%) developed TB giving an overall incidence density rate of 4.25/100PYR (95\% CI: 2.47-6.46). With respect to the age groups, patients within the age group $0-20$ years constituted just $4.5 \%$ of the study population with TB incidence density rate of $3.89 / 100$ PYR $(95 \%$ CI: 0.73 5.61), those who were between the ages of 21-40 years, constituted the highest proportion $(60.5 \%)$ of the study population and had TB incidence density rate of $4.22 / 1000$ PYR (95\% CI: 1.40-4.68). Patients whose ages were $\geq 60$ constituted the least proportion $(2.9 \%)$ of the study participants and the least TB incidence density rate of 2.92/1000 PYR (CI: 0.91-3.00). The difference between TB incidence density rate in the different age groups was not statistically significant $(P=0.907)$.

With respect to gender, TB incidence density rate was higher in males (5.30/100 PYR) (95\% CI: 0.89-6.94) compared to females (3.82 /100 PYR) (CI: 2.23-3.90) but the difference between the groups was not statistically significant $(p=0.25)$. TB incidence density rate was high $(6.51 / 100$ PYR, CI: 0.71-7.14) among patients who were smoker compared to those who did not smoke $(4.15 / 100 \mathrm{PYR}, \mathrm{CI}$ : 2.40-5.40). With respect to WHO HIV clinical staging, more than half $(56.5 \%)$ of the patients were either in stages 3 or 4 and had a TB incidence density rate of 4.89 /100PYR, (CI: 2.10-6.81). Those with stages 1 and 2 had a TB incidence density rate of $3.39 / 100$ PYR (CI: 1.46-4.80). There was a significance difference in the incidence density rate between those in stage 1and 2 and those in stage 3 and $4(P=0.013)$. Similarly, there was a significant difference in the incidence of TB in those with CD4 cells $\leq 200$ cells $/ \mu 1(4.72 / 100$ PYR, CI: 2.64-5.12) and those CD4 cells $>200$ cells $/ \mu 1(3.72 / 100$ person years, CI: 2.20 -2.9) (Table 2).

Table 2. Tuberculosis incidence density rate stratified by baseline Sociodemographic and clinical characteristics of patients.

\begin{tabular}{|c|c|c|c|c|c|}
\hline \multirow{2}{*}{ Variables } & \multirow{2}{*}{ Number of patients, $n$ (\%) } & \multirow{2}{*}{ Person years } & \multirow{2}{*}{ Number of TB cases, $n$ (\%) } & TB IDR & \multirow{2}{*}{ P-value } \\
\hline & & & & $(95 \% \mathrm{CI})$ & \\
\hline Total No of patients & 1477 & 4915.5 & $209(14.2)$ & $4.25(2.47-6.46)$ & \\
\hline \multicolumn{6}{|l|}{ Age/years } \\
\hline $0-20$ & $67(4.5)$ & 201.5 & $8(3.8)$ & $3.89(0.73-5.61)$ & \multirow{4}{*}{0.907} \\
\hline $21-40$ & $894(60.5)$ & 2890.5 & $122(58.4)$ & $4.22(1.40-4.68)$ & \\
\hline $41-60$ & $473(32)$ & 1652 & $74(35.4)$ & $4.48(2.10-5.32)$ & \\
\hline $60+$ & $43(2.9)$ & 171.5 & $5(2.4)$ & $2.92(0.91-3.00)$ & \\
\hline \multicolumn{6}{|l|}{ Gender } \\
\hline Males & $433(29.3)$ & 1411.5 & $75(35.9)$ & $5.30(0.89-6.94)$ & \multirow{2}{*}{0.25} \\
\hline Females & $1044(70.7)$ & 3504.0 & $134(64.1)$ & $3.82(2.23-3.90)$ & \\
\hline \multicolumn{6}{|l|}{ Smoking status } \\
\hline Yes & $74(5.0)$ & 215.5 & $14(6.7)$ & $6.51(0.71-7.14)$ & \multirow{2}{*}{0.001} \\
\hline No & $1403(95.0)$ & 4700 & $195(93.3)$ & $4.15(2.40-5.40)$ & \\
\hline \multicolumn{6}{|l|}{ WHO clinical staging } \\
\hline Stage 1 and 2 & $634(42.9)$ & 2094.5 & $71(34.0)$ & $3.39(1.46-4.80)$ & \multirow{2}{*}{0.013} \\
\hline Stage 3 and 4 & $843(57.1)$ & 2821.0 & $138(66.0)$ & $4.89(2.10-6.81)$ & \\
\hline \multicolumn{6}{|l|}{ CD4 count cell count } \\
\hline$\leq 200$ & $760(51.5)$ & 2558.5 & $121(58.7)$ & $4.72(2.64-5.12)$ & \multirow{2}{*}{0.035} \\
\hline$>200$ & $717(48.5)$ & 2357.0 & $88(41.3)$ & $3.72(2.20-5.90)$ & \\
\hline \multicolumn{6}{|l|}{ Anaemia status } \\
\hline Non-anaemic & $527(35.7)$ & 1830.5 & $60(28.7)$ & $3.28(1.21-6.23)$ & \multirow{4}{*}{0.431} \\
\hline Mild anaemia & $452(30.6)$ & 1452.5 & $71(34.0)$ & $4.89(2.5-8.13)$ & \\
\hline Moderate anaemia & $346(23.4)$ & 1149 & $52(24.9)$ & $4.53(2.9-7.41)$ & \\
\hline Severe anaemic & $152(10.3)$ & 470 & $26(12.4)$ & $5.53(3.10-8.91)$ & \\
\hline
\end{tabular}

TB IDR: TB Incidence Density Rate, CI: Confidence Interval.

\subsection{Incidence of TB Stratified by Year of Commencement of $A R T$}

Table 3 below depicts the number of TB cases diagnosed each year and the corresponding incidence density rates. This study revealed that, there have been an increase in the number of HIV cases registered from 2008 to 2013 and a drop in 2014, meanwhile TB incidence density rate increases steadily from 2008 to 2013 and a remarkable increase in 2014 i.e. from 8.33/100 PYR (95\% 2.43-10.07) to 19.34 (95\%CI: 7.36-21.20).

\subsection{Trend in TB Incidence Over the Last 7 Years (2008 - 2014)}

The incidence rate increased from $1.69 / 1000$ PYR in 2008 to $2.92 / 1000 \mathrm{PYR}$ in 2009 , then dropped to $2.40 / 1000$ PYR in 2010 and from 2011 to 2013 , there was a steady increase in the incidence rate from $2.93 / 100 \mathrm{PYR}$ to $8.33 / 1000$. PYR, Also, the incidence rate in 2014 was almost 3 times the incidence in 2013, i.e. from $8.33 / 1000 \mathrm{PYR}$ to 19.63/1000PYR (Figure 2). 


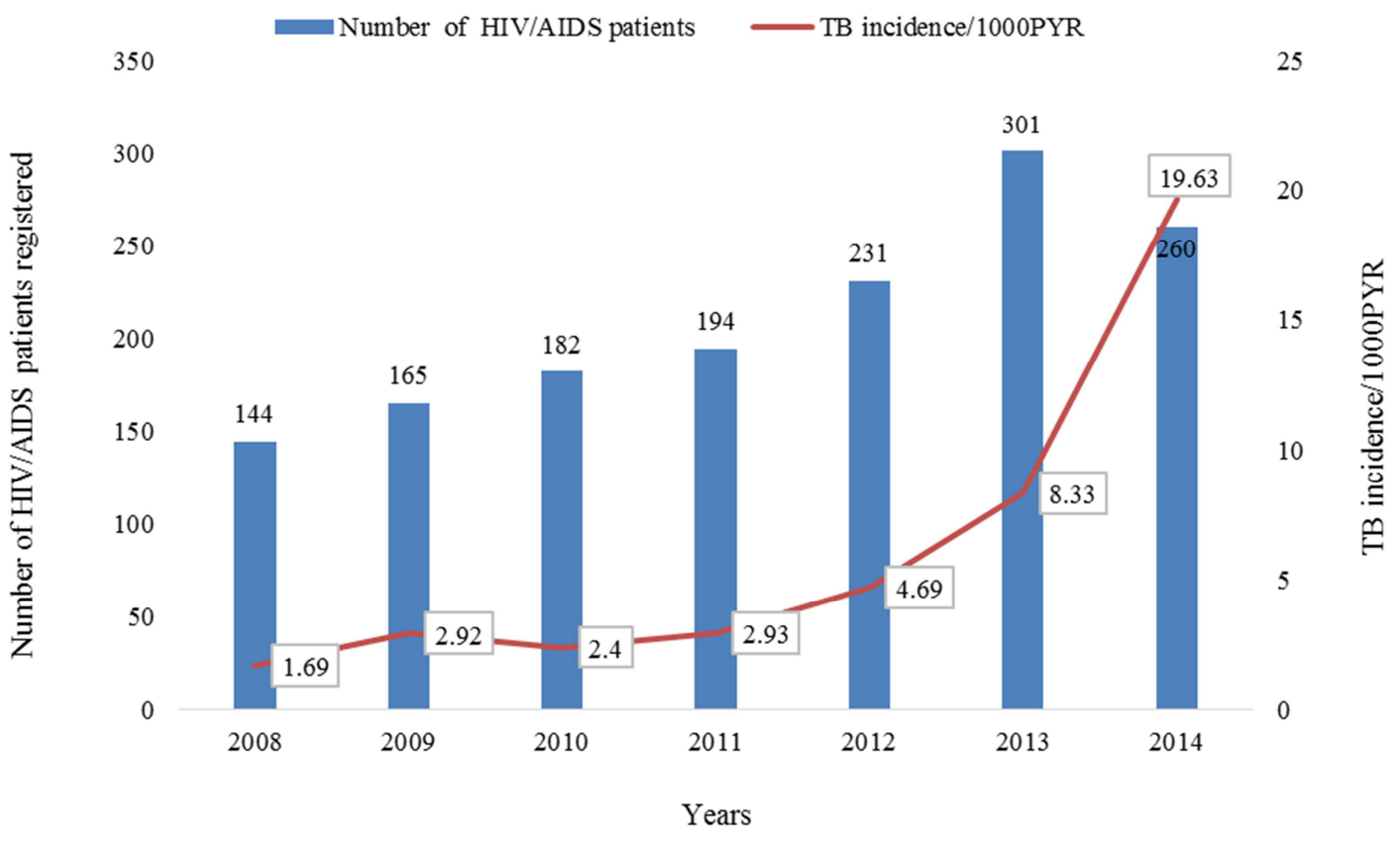

Figure 2. Trends in TB incidence over the last 7 years compared to number of HIV patients registered at the treatment centre.

\subsection{Socio-demographic and Clinical Risk Factors of Developing TB in HIV Patients}

Table 3 describes socio-demographic and clinical risk of TB among HIV patients. Considering a cut-off p-value of $\leq$ 0.2 , in the bivariate analysis, the following factors appeared to be risk factors to developing $\mathrm{TB}$, gender, $\mathrm{WHO}$, clinical stage of HIV and CD4 count levels at initiation of treatment. In the multiple binary logistic regression, after controlling for potential confounding variables; WHO stage of HIV and the level of CD4 count cells at initiation of treatment had statistically significant association with the development of
TB based on a cut-off $p$-value of $<0.05$. The risk of developing TB in HIV patients who were in WHO stage 3 and 4 was 1.5 times (CI: 0.91-2.22) higher than those in stage 1 and 2. Likewise, patients with CD4 count level $\leq 200$ cell $/ \mu \mathrm{l}$ were 1.3 times (CI: 0.51-.2.10) more at risk of developing TB than those with CD4 greater than 200 cells $/ \mu 1$. Although not statistically significant, the risk of developing TB among males was 1.2 times (CI 1.52-1.84) higher than that of females. There was no statistical significance between, smoking status, alcohol and the development of TB, though they may also be risk factor (Table 3).

Table 3. Socio-demographic and clinical risk factors of developing TB in HIV patients.

\begin{tabular}{|c|c|c|c|c|c|c|}
\hline \multirow{2}{*}{ Variables } & \multicolumn{2}{|c|}{ Prevalence, n (\%) } & \multicolumn{2}{|c|}{ Bivariate logistic regression } & \multicolumn{2}{|c|}{ Multivariate logistic regression } \\
\hline & TB Cases & Non-TB cases & OR $(95 \%$ CI) & $P$-value & AOR $(95 \%$ CI) & P-value \\
\hline \multicolumn{7}{|l|}{ Sex } \\
\hline Females & $134(64.1)$ & $910(71.8)$ & 1 & - & - & \\
\hline Males & $75(35.9)$ & $358(28.2)$ & $1.2(0.52-1.84)$ & 0.43 & - & \\
\hline \multicolumn{7}{|l|}{ Age } \\
\hline $0-20$ & $8(3.8)$ & $59(4.7)$ & 1 & - & - & \\
\hline $21-40$ & $122(58.4)$ & $772(60.9)$ & $1.1(0.46-2.63)$ & 0.83 & - & \\
\hline $41-60$ & $74(35.4)$ & $399(31.5)$ & $1.2(0.49-2.91)$ & 0.70 & - & \\
\hline $60+$ & $5(2.4)$ & $38(3.2)$ & $0.8(0.19-3.41)$ & 0.76 & - & \\
\hline \multicolumn{7}{|l|}{ WHO staging } \\
\hline Stage 1 and 2 & $71(34.0)$ & $563(44.4)$ & 1 & - & 1 & \multirow{2}{*}{0.03} \\
\hline Stage 3 and 4 & $138(66.0)$ & $705(55.6)$ & $1.6(1.09-2.33)$ & 0.01 & $1.52(1.01-2.22)$ & \\
\hline \multicolumn{7}{|c|}{ CD4+ cell at initiation } \\
\hline$>200 \mathrm{cell} / \mu \mathrm{l}$ & $121(57.9)$ & 639 (50.4.) & 1 & - & 1 & \multirow{2}{*}{0.04} \\
\hline$\leq 200$ cells $/ \mu 1$ & $88(42.1)$ & $629(49.6)$ & $1.5(1.02-2.10)$ & 0.02 & $1.3(1.11-.2 .10)$ & \\
\hline \multicolumn{7}{|l|}{ Smoking status } \\
\hline No & $195(93.3)$ & $1208(95.3)$ & 1 & - & - & \multirow[b]{2}{*}{-} \\
\hline Yes & $14(6.7)$ & $60(4.7)$ & $1.3(0.67-2.66)$ & 0.05 & - & \\
\hline \multicolumn{7}{|l|}{ Alcohol } \\
\hline Yes & $79(39.8)$ & $537(43.5)$ & 1 & - & - & \\
\hline No & $130(62.2)$ & $717(56.5)$ & $1.2(0.69-1.40)$ & 0.9 & - & \\
\hline
\end{tabular}




\begin{tabular}{|c|c|c|c|c|c|c|}
\hline \multirow{2}{*}{ Variables } & \multicolumn{2}{|c|}{ Prevalence, n (\%) } & \multicolumn{2}{|c|}{ Bivariate logistic regression } & \multicolumn{2}{|c|}{ Multivariate logistic regression } \\
\hline & TB Cases & Non-TB cases & OR $(95 \%$ CI $)$ & $P$-value & $\operatorname{AOR}(95 \% \mathrm{CI})$ & P-value \\
\hline \multicolumn{7}{|l|}{ Education al level } \\
\hline No-school & $3(5.8)$ & $33(2.6)$ & 1 & - & - & \multirow{4}{*}{ - } \\
\hline Primary & $72(34.4)$ & $559(44.1)$ & $1.1(0.74-1.56)$ & 0.69 & - & \\
\hline Secondary & $108(51.7)$ & $564(44.5)$ & $0.9(0.46-1.88)$ & 0.85 & - & \\
\hline Tertiary & $26(12.4)$ & $112(8.8)$ & $0.9(0.26-2.99)$ & 0.85 & - & \\
\hline \multicolumn{7}{|l|}{ Occupation } \\
\hline Farmers & $56(21.7)$ & $321(25.5)$ & 1 & - & - & \multirow{5}{*}{-} \\
\hline Employed & $37(21.0)$ & $228(23.8)$ & $1.3(0.74-2.17)$ & 0.37 & - & \\
\hline Housewife/no job & $13(6.2)$ & $88(6.8)$ & $1.3(0.63-2.59)$ & 0.50 & - & \\
\hline Business & $92(44.1)$ & $528(37.2)$ & $1.2(0.76-1.92)$ & 0.43 & - & \\
\hline Student & $11(5.3)$ & $103(6.0)$ & $0.9(0.45-2.14)$ & 0.95 & - & \\
\hline
\end{tabular}

\subsection{Mortality Rate Due to All Causes Among HIV Patients Between 2008 and 2014 Inclusive}

Of the 1477 patients that were placed on antiretroviral treatment between 2008 and 2014 inclusive, 183 of them died giving an all-cause mortality rate of $12.4 \%$ (Figure 3 ).

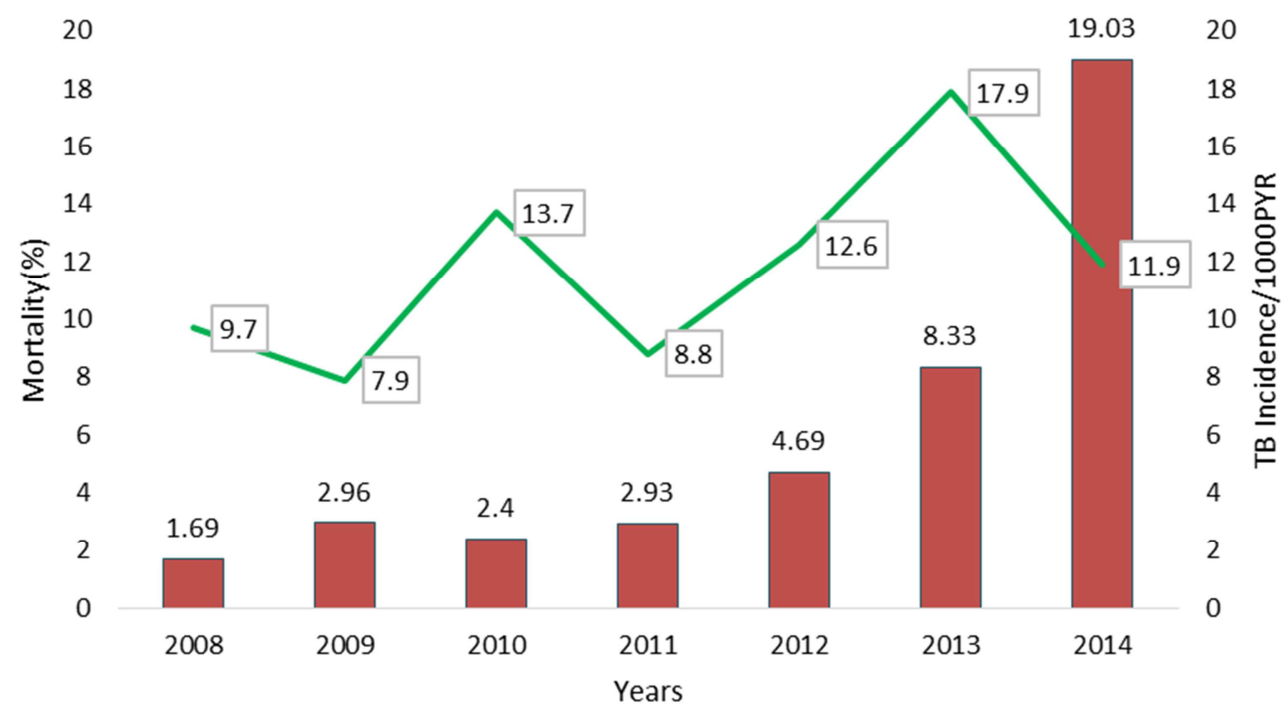

\footnotetext{
$\square$ TB incidence $\longrightarrow$ Mortality rate

Figure 3. Mortality rate among HIV patients between 2008 and 2014 inclusive.
}

\section{Discussion}

TB remains one of the most common opportunistic infections among HIV infected persons with 10 - 15 times more likely to develop active TB disease than persons HIV negative individuals. $[17,18]$ This hospital-based retrospective cohort study shows that $14.2 \%$ (209) of all HIV-infected individuals on ART in the Buea treatment centre developed TB during the last 7 years of follow-up. Majority (64.1\%) of these 209 TB cases were females. Cameroon, like many sub-Saharan Africa countries with a high burden of HIV and TB coinfections the proportion of TB disease in all individual infected with HIV in our study was higher than reports in developed countries such Spain $(7.7 \%)$ and the US. $[17,19]$

The incidence density rate of TB among individuals infected with HIV/AIDS in this study was 4.25 cases /1000
PYR which was relatively higher than that reported in a generalised HIV epidemic setting such as South Africa (1.01/1000 PYR). [20] Poor adherence to ART has been shown to account for such high incidence of TB among patients on ART. Generally non-adherence to ART is associated with high propensity of both virologic and immunological failure and therefore TB sets in with a decline in immunological status [21]. Though not statistically significant, the incidence rate of 5.30/1000PYR, in males was higher than that in females, 3.82/100 PYR. This is similar with a study conducted in Nigeria Guadeloupe and India. [11, 22, 23] However, this contradicts findings in 2011 in South Africa by lawn et al. where they showed that TB incidence in females was $3.15 / 100 \mathrm{PYR}$ compared to 1.9/100PYR in males. [20] Other contributing factors that put men at a higher risk of TB is smoking which in our study revealed most of those men who had TB were smokers. [24] 
Corroborating a study conducted in 2013 by Elonga et al. [22], the incidence of TB among patients who were at WHO clinical stage 3 and 4 of HIV infection was significantly higher $(P=0.013)$ than in those who were in clinical stage 1 and 2 (4.89/1000PYR versus 3.39/1000PYR). Similarly, TB incidence was higher (4.72/1000 PYR (CI: 2.10-6.81, $P=0.013$ ) in in those with CD4 $\leq 200$ cell $/ \mu 1$ compared to those with CD4 cells $>200$ cells/ $\mu$ l (3.72/1000 PYR, CI: 2.20-5.90) and this result is consistent with studies conducted in both low- and highincome countries. A study in Germany showed that the incidence of TB was high in those with a CD4 $\leq 200$ cells $/ \mu 1$ compared to those with CD4 $>200$ cells/ $\mu 1$ [25], while in South Africa, the incidence of TB in those with CD4 $\leq 200$ cells $/ \mu 1$ was three times higher when compared to those with a CD4 $>200$ cells $/ \mu$ l. Patients with low CD4 cells level are highly immunocompromised with a corresponding high viremia, this therefore reactivate latent $\mathrm{TB}$ which is common in $\mathrm{TB}$ endemic regions resulting in high incidence rate of active $\mathrm{TB}$ as compared to those with high CD4 cells.

The study also revealed that the number of HIV cases increased as the years go by. This could be as a result of improving public sensitization and awareness coupled with regulars screening activities, and improvement in diagnostic techniques as such new HIV cases are being diagnosed. However, because of an increase in the number of HIV cases over the years, there is also a corresponding increase in the number of TB cases over the years. This can be explained by the fact that HIV is a predisposing factor to active TB. [4] This study also demonstrated that baseline blood CD4 cell count at ART initiation and WHO HIV clinical staging were all independently associated with an increased risk of TB. In the unadjusted analyses, baseline CD4, WHO HIV clinical staging and smoking were all associated with increased risk of TB. In the multivariate logistic regression model, after adjusting for confounders, only two factors were significantly associated with increased risk of TB i.e. baseline CD4+ cells $(P=0.04)$ and WHO HIV clinical staging $(P=0.03)$. This finding is consistent with other findings from studies done in developing and industrialized countries which reported that lower CD4+ cell count at enrolment were independently associated with higher risk of TB. [26, 27] Patients who were in stages 3 and 4 were 1.5 times more at risk of developing TB compared to those in stages 1 and $2(P=0.03)$. This could be due to the fact patients who are in stages 3 and 4 have an increase in viral load and a decrease in CD4 load hence paving the way for latent TB to be converted to active TB. Patients whose CD $\leq 200$ cells/ $\mu$ l were 1.3 times more at risk compared to those with CD4 $>200$ cells/ $\mu$ l. Studies conducted in South Africa reported similar results. [26] Age, gender, smoking history and alcohol were not significantly associated with increased risk of TB which holds true with findings in Ethiopia by mulugeta et al. in 2016. [27]

The mortality rate found in this study was $12.4 \%$, exceedingly higher than the $4 \%$ reported in a similar study carried out in the United States. [27] Studies carried out in
South Africa reported death rate lower than what we got here. The high mortality rate in our study could be attributed to the high default rate among the patients. [28] With respect to trend in mortality rate over the years it was revealed that mortality rate dropped from $9.7 \%$ in 2008 to $7.9 \%$ in 2009 then increased to $13.7 \%$ in 2010 and dropped to $8.8 \%$ in 2011 and then increased to $17.9 \%$ in 2013 . Then declined to $11.9 \%$ in 2014. The high mortality reported in this study could be due to an increase in poor compliance to ART and as such creating opportunities for opportunistic diseases and consequently death. The study also showed that a majority $(70.7 \%)$ of HIV patients were females. this is in line with studies conducted in Nigeria which revealed that more females are infected with HIV than males. [29] This could be due to the fact women have a higher susceptibility to HIV infection due to the nature of the anatomy of their sex organs. Also, they are usually exposed to sexual activities earlier than men mainly due to economic circumstances. Furthermore, most African women are so subordinated to their husbands that they have little or no say in issues related to sexual relationships hence it's possible for a man to be a source of infection to so many women. [30]

\section{Conclusions}

The incidence of TB and mortality due to TB in this study was high and this incidence increases with increase in years. Factors significantly associated with the development of TB among HIV patients were WHO stage of HIV and the level of CD4 count cells at initiation of treatment. Also, the number of HIV positive cases keep increasing with years. This study showed that even in the era of HAART, TB still remains a significant cause of mortality among PLHIV and therefore efforts should be scaled-up to diagnosis and treatment of TB promptly.

\section{Limitation of this Study}

This study was a retrospective cohort study. Although efforts were made to control for confounders at the design and analyses levels, unidentified confounders may still have affected the observations. In addition, because this was a retrospective cohort study based on reviewing of patients records and some information were either absent or incompletely filled which could affect the findings. Also, there are many risks factors that expose HIV patients to TB which all were not found in the records and so we considered only those that could be found in the patients' record form which could influence the interpretation of the results. The 183 patients who died were considered to have died of HIV/AIDS, though they might have died of other courses since the causes were not documented. This consideration might have affected the overall mortality rate.

\section{Conflict of Interest}

The authors declare that they have no competing interests. 


\section{Abbreviation}

$\begin{array}{ll}\text { PLHIV } & \text { People Living with HIV } \\ \text { TB } & \text { Tuberculosis } \\ \text { HIV } & \text { Human Immune Deficiency Syndrome } \\ \text { HAART } & \text { Highly Active Antiretroviral Treatment } \\ \text { WHO } & \text { World Health Organisation } \\ \text { PYR } & \text { Person Year } \\ \text { CI } & \text { Confidence Interval } \\ \text { AOR } & \text { Adjusted Odd Ratio }\end{array}$

\section{Funding}

The authors did not receive specific support or funding for this study.

\section{Acknowledgements}

We are grateful to the staff of the HIV/TB treatment center of the Buea Regional Hospital for the support they gave us during this study.

\section{References}

[1] Habib AG. A clinical and epidemiologic update on the interaction between tuberculosis and human immunodeficiency virus infection in adults. Ann Afr Med. 2009; 8: 147-55. doi: 10.4103/1596-3519.57236.

[2] WHO. Global Tuberculois Report 2015- Executive Summary. World Heal Organ. 2015; 1-3. doi: 10.1037/e530172011-002.

[3] World Health Organization. Global Tuberculosis Report [Internet]. WHO. 2013. doi: 9789241564502.

[4] Corbett EL, Watt CJ, Walker N, Maher D, Williams BG, Raviglione MC, et al. The growing burden of tuberculosis: global trends and interactions with the HIV epidemic. Arch Intern Med. 2003; 163: 1009-21. doi: 10.1001/archinte. 163.9.1009.

[5] Wang L, Liu W, Wang Y, Wu Z. HIV prevalence among pulmonary tuberculosis patients in Guangxi, China. J Acquir Immune Defic Syndr. 2010; 53 Suppl 1: S61-5. doi: 10.1097/QAI. 0b013e3181c7db2e.

[6] Jaryal A, Raina R, Sarkar M, Sharma A. Manifestations of tuberculosis in HIV/AIDS patients and its relationship with CD4 count. Lung India. 2011; 28: 263-6. doi: 10.4103/09702113.85687.

[7] Chaimay B, Woradet S, Chantutanon S, Phuntara S, Suwanna K. Mortality among HIV/AIDS patients coinfected with Mycobacterium tuberculosis in southern Thailand. Southeast Asian J Trop Med Public Health. 2013; 44: 641-648. Available: http://www.ncbi.nlm.nih.gov/pubmed/24050098.

[8] WHO. HIV-Associated Tuberculosis. Eur Med J. 2015; 60: 60-70.

[9] WHO. Antiretroviral therapy for HIV infection in adults and adolescents. Recommendations for a public health approach: 2010 revision. World Heal Organ. 2010.

[10] Mor Z, Lidji M, Cedar N, Grotto I, Chemtob D. Tuberculosis incidence in HIV/AIDS patients in Israel, 1983-2010. PLoS
One. 2013; 8. doi: 10.1371/journal.pone. 0079691.

[11] Wasa Alibe Ahmed RKP and BYB. Incidence of Tuberculosis among Human Immunodeficiency Virus (HIV) patients attending General Hospital Bajogaln. IOSR J Pharm Biol Sci. 2013; 7: 69-72. Available: http://www.iosrjournals.org/iosrjpbs/papers/Vol7-issue5/L0756972.pdf?id=6973.

[12] Carvalho BM De, Monteiro AJ, Pires Neto RDJ, Grangeiro TB, Frota CC. Factors related to HIV/tuberculosis coinfection in a Brazilian reference hospital. Braz J Infect Dis. 2008; 12: 281-286. doi: 10.1590/S1413-86702008000400005.

[13] Mukadi YD, Maher D, Harries A. Tuberculosis case fatality rates in high HIV prevalence populations in sub-Saharan Africa. AIDS. 2001; 15: 143-152. doi: 10.1097/00002030200101260-00002.

[14] Batista J d AL, de Albuquerque $M$ de FPM, Maruza M, Ximenes RA de A, Santos ML, Montarroyos UR, et al. Incidence and Risk Factors for Tuberculosis in People Living with HIV: Cohort from HIV Referral Health Centers in Recife, Brazil. PLoS One. 2013; 8. doi: 10.1371/journal.pone. 0063916.

[15] Libite PR, Kelodjoue S, Dzossa a D, Fomo M a, Niekou R, Al. E, et al. Republic of Cameroon: Demographic and Health Survey and Multiple Indicator Cluster Survey (DHS-MICS) 2011. / République du Cameroun: enquête démographique et de santé et à indicateurs multiples (EDS-MICS) 2011. [Internet]. République du Cameroun: enquête démographique et de santé et à indicateurs multiples (EDS-MICS) 2011. 2012. Available: http://www.measuredhs.com/pubs/pdf/FR260/FR260.pdf.

[16] Howard AA, El-Sadr WM. Integration of tuberculosis and HIV services in sub-Saharan Africa: lessons learned. Clin Infect Dis. 2010; 50 Suppl 3: S238-44. doi: 10.1086/651497.

[17] Muga R, Ferreros I, Langohr K, de Olalla PG, Romero J Del, Quintana M, et al. Changes in the incidence of tuberculosis in a cohort of HIV-seroconverters before and after the introduction of HAART. AIDS. 2007; 21: 2521-2527. doi: 10.1097/QAD. 0b013e3282f1c933.

[18] Dalbo M, Tamiso A, Dalbo M, Tamiso A. Incidence and Predictors of Tuberculosis among HIV/AIDS Infected Patients: A Five-Year Retrospective Follow-Up Study. Adv Infect Dis. 2015; 6: 70-81. doi: 10.4236/aid. 2016.62010.

[19] Hanna DB, Gupta LS, Jones LE, Thompson DM, Kellerman SE, Sackoff JE. AIDS-defining opportunistic illnesses in the HAART era in New York City. AIDS Care. 2007; 19: 264272. doi: $10.1080 / 09540120600834729$.

[20] Lawn SD, Badri M, Wood R. Tuberculosis among HIVinfected patients receiving HAART: long term incidence and risk factors in a South African cohort. AIDS. 2005. pp. 2109 2116. doi: 10.1097/01.aids. 0000194808.20035.c1.

[21] Charurat M, Oyegunle M, Benjamin R, Habib A, Eze E, Ele P, et al. Patient Retention and Adherence to Antiretrovirals in a Large Antiretroviral Therapy Program in Nigeria: A Longitudinal Analysis for Risk Factors. PLoS One. 2010; 5: e10584. doi: 10.1371/journal.pone. 0010584.

[22] Elenga N, Georger-Sow M-T, Messiaen T, Lamaurie I, Favre I, Nacher M, et al. Incidence, predictive factors and prognosis of tuberculosis among patients with hiv infection in guadeloupe 1988-2009. J AIDS Clin Res. 2013; 4. Available: http://www.scopus.com/inward/record.url?eid=2-s2.084884937610\&partnerID=40\&md5=8bbef65ad4b7956e91131 $8 \mathrm{bc} 876 \mathrm{~b} 444 \mathrm{f}$. 
[23] Gopi PG, Subramani R, Santha T, Kumaran PP, Kumaraswami V, Narayanan PR. Relationship of ARTI to incidence and prevalence of tuberculosis in a district of south India. International Journal of Tuberculosis and Lung Disease. 2006. pp. 115-117.

[24] Murrison LB, Martinson N, Moloney RM, Msandiwa R, Mashabela M, Samet JM, et al. Tobacco smoking and tuberculosis among men living with hiv in johannesburg, South Africa: A case-control study. PLoS One. 2016; 11: e0167133. doi: 10.1371/journal.pone. 0167133.

[25] Karo B, Haas W, Kollan C, Gunsenheimer-Bartmeyer B, Hamouda O, Fiebig L. Tuberculosis among people living with HIV/AIDS in the German ClinSurv HIV Cohort: long-term incidence and risk factors. BMC Infect Dis. BMC Infectious Diseases; 2014; 14: 148. doi: 10.1186/1471-2334-14-148.

[26] Lawn SD, Bekker L-G, Wood R. How effectively does HAART restore immune responses to Mycobacterium tuberculosis? Implications for tuberculosis control. Aids. 2005; 19: 1113-1124. doi: 10.1097/01.aids. 0000176211.08581.5a.
[27] Girardi E, Antonucci G, Vanacore P, Palmieri F, Matteelli a, Iemoli E, et al. Tuberculosis in HIV-infected persons in the context of wide availability of highly active antiretroviral therapy. Eur Respir J Off J Eur Soc Clin Respir Physiol. 2004; 24: 11-17. doi: 10.1183/09031936.04.00109303.

[28] Taarnhøj G a, Engsig FN, Ravn P, Johansen IS, Larsen CS, Røge $\mathrm{B}$, et al. Incidence, risk factors and mortality of tuberculosis in Danish HIV patients 1995-2007. BMC Pulm Med. 2011; 11: 26. doi: 10.1186/1471-2466-11-26.

[29] Pennap GR, Makpa S, Ogbu S. PREVALENCE OF HIV/AIDS AMONG TUBERCULOSIS PATIENTS SEEN IN A RURAL CLINIC IN NIGERIA. Trakia J Sci. 2011; 9: 40-44. Available: http://www.uni-sz.bg.

[30] Nwobu GO, Okodua MA, Tatfeng YM. Comparative study of HIV associated pulmonary tuberculosis in chest clinics from two regions of Edo state, Nigeria. JHAS. 2004; 3: 1-7. Available:

https://pdfs.semanticscholar.org/191b/8271c50b0ac1f7933b1e cc06966f09e360c2.pdf. 